\title{
Pulmonary strongyloidiasis: assessment between manifestation and radiological findings in 16 severe strongyloidiasis cases
}

Daijiro Nabeya* ${ }^{*}$, Shusaku Haranaga, Gretchen Lynn Parrott, Takeshi Kinjo, Saifun Nahar, Teruhisa Tanaka,

Tetsuo Hirata, Akira Hokama, Masao Tateyama and Jiro Fujita

\begin{abstract}
Background: Strongyloidiasis is a chronic parasitic infection caused by Strongyloides stercoralis. Severe cases such as, hyperinfection syndrome (HS) and disseminated strongyloidiasis (DS), can involve pulmonary manifestations. These manifestations frequently aid the diagnosis of strongyloidiasis. Here, we present the pulmonary manifestations and radiological findings of severe strongyloidiasis.

Methods: From January 2004 to December 2014, all patients diagnosed with severe strongyloidiasis at the University of the Ryukyus Hospital or affiliated hospitals in Okinawa, Japan, were included in this retrospective study. All diagnoses were confirmed by the microscopic or histopathological identification of larvae. Severe strongyloidiasis was defined by the presence of any of the following: 1) the identification of S. stercoralis from extra gastrointestinal specimens, 2) sepsis, 3) meningitis, 4) acute respiratory failure, or 5) respiratory tract hemorrhage. Patients were assigned to either HS or DS. Medical records were further reviewed to extract related clinical features and radiological findings.

Results: Sixteen severe strongyloidiasis cases were included. Of those, fifteen cases had pulmonary manifestations, eight had acute respiratory distress syndrome (ARDS) (53\%), seven had enteric bacterial pneumonia (46\%) and five had pulmonary hemorrhage (33\%). Acute respiratory failure was a common indicator for pulmonary manifestation (87\%). Chest X-ray findings frequently showed diffuse shadows (71\%). Additionally, ileum gas was detected for ten of the sixteen cases in the upper abdomen during assessment with chest $X$-ray. While, chest $C T$ findings frequently showed ground-glass opacity (GGO) in 89\% of patients. Interlobular septal thickening was also frequently shown (67\%), always accompanying GGO in upper lobes.

Conclusions: In summary, our study described HS/DS cases with pulmonary manifestations including, ARDS, bacterial pneumonia and pulmonary hemorrhage. Chest X-ray findings in HS/DS cases frequently showed diffuse shadows, and the combination of GGO and interlobular septal thickening in chest CT was common in HS/DS, regardless of accompanying pulmonary manifestations. This $\subset$ finding suggests alveolar hemorrhage could be used as a potential marker indicating the transition from latent to symptomatic state. Respiratory specimens are especially useful for detecting larvae in cases of HS/DS.
\end{abstract}

Keywords: Acute respiratory distress syndrome, Bacterial pneumonia, Interlobular septal thickening, Pulmonary alveolar hemorrhage, pulmonary strongyloidiasis

\footnotetext{
* Correspondence: respiratoryyy@gmail.com

Department of Infectious Diseases, Respiratory, and Digestive Medicine,

Graduate School of Medicine, University of the Ryukyus, 207 Uehara, Nishihara,

Okinawa 903-0215, Japan
} 


\section{Background}

Strongyloidiasis is a chronic parasitic infection caused by Strongyloides stercoralis. Strongyloidiasis is occasionally recognized as a "neglected tropical disease" [1-4]. Previous reports have estimated 30 to 100 million infected persons worldwide [5-7], with some reports predicting a high likelihood of increase [8]. However, due to increasing globalization and immigration, the development of symptomatic strongyloidiasis and diagnosis of strongyloidiasis may become problematic for non-endemic areas $[9,10]$. As such, there is a chance for symptomatic patients with strongyloidiasis living in non-endemic countries to spread the disease exponentially.

This parasite has unique life cycle (Fig. 1). Filariform larvae, which inhabit the soil, infect humans via skin penetration. After infection, the larvae travel hematogenously to the lung and then escape to alveolar space. The larvae then migrate to the pharynx and are swallowed, producing eggs in the upper small intestine. Rhabditiform larvae, hatched from eggs, are usually excreted from the human host. However, some rhabditiform larvae can mature into filariform larvae within the bowel, and re-infect their host via the intestinal mucosa or perianal skin. This re-infection process, called auto-infection, allows $S$. stercoralis to complete its life cycle and proliferate successfully within a single host $[7,11,12]$. As such, it is possible for S. stercoralis to infect a host for years or decades without detection [13].
The majority of infected patients are asymptomatic or present only mild gastrointestinal symptoms [10, 14-16]. However, some patients, such as those with advanced age, malnutrition, those using an immunosuppressant including steroids, or those with diabetes mellitus and human T-cell leukemia virus type 1 (HTLV-1) can progress to hyperinfection syndrome (HS), characterized by complications due to uncontrolled proliferation of larvae, and disseminated strongyloidiasis (DS), characterized by disseminating to organs not involved in the life-cycle of $S$. stercoralis in humans $[7,14,15,17-20]$. Because patients with HS/DS are often at risk for further complications like sepsis and/or meningitis, the fatalities within this group are common, ranging from 60 to $80 \%[9,17,21]$. Interestingly, HS/DS can also involve pulmonary manifestations [17, 22-24]. Often called, pulmonary strongyloidiasis, this manifestation can facilitate the diagnosis of strongyloidiasis. Although some reports discuss radiological findings using chest X-ray [17, 25], no published data exists to our knowledge comparing pulmonary manifestations with the radiological findings of chest CT in severe strongyloidiasis cases.

In an effort to lessen this knowledge gap, we present the pulmonary manifestations for sixteen cases of severe strongyloidiasis from Okinawa, Japan, a subtropical region previously considered endemic for S. stercoralis [26, 27].

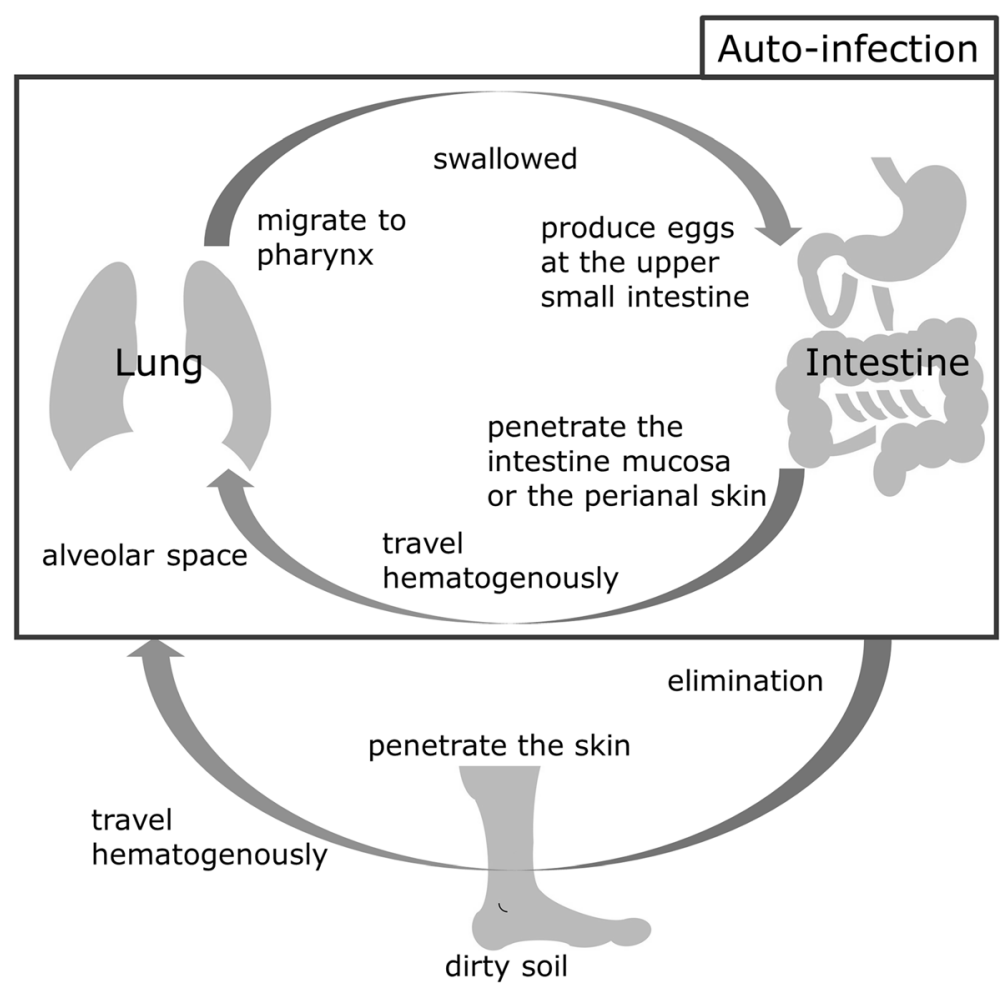

Fig. 1 Lifecycle of Strongyloides stercoralis 


\section{Methods}

From January 2004 to December 2014, all patients diagnosed with severe strongyloidiasis at the University of the Ryukyus Hospital or affiliated hospitals in Okinawa, Japan, were included in this retrospective study. All diagnoses were confirmed by the microscopic identification of larvae using the agar plate culture method [11] or histopathological findings. For purposes of this study, severe strongyloidiasis was defined by the presence of any of the following: 1) the identification of S. stercoralis from extra gastrointestinal specimens, 2) sepsis, 3) meningitis, 4) acute respiratory failure, or 5) respiratory tract hemorrhage. Severe cases were assigned to DS when larvae were found in any organ, other than those within the respiratory and gastrointestinal tracts (organs not involved in the life-cycle of S. stercoralis in humans). Other cases were assigned to HS. Medical records were reviewed to extract any relevant and related clinical features.

Radiological findings of chest X-ray (CXR) and chest computed tomography (CCT) taken at the onset of HS/ DS were also reviewed. If CXR or CCT was performed multiple times, an image from the date closest to onset was chosen for radiological assessment. All radiological findings were reviewed by two respirologists, and two gastroenterologists checked for the existence of ileum gas using the same CXR. Patients with a simultaneous underlying pulmonary disease were excluded from the analysis of radiological findings, due to difficulties in identifying the root cause of radiological findings.

The study was reviewed and approved by the Clinical Research Ethics Committee of University of the Ryukyus (H26.8-7-695).

\section{Results}

\section{Patient characteristics}

In total, sixteen severe strongyloidiasis cases were collected: three DS and thirteen HS (Tables 1, 2). Fourteen cases had detectable $S$. stercoralis in extragastrointestinal specimens. Of importance, thirteen of those fourteen cases could be detected from respiratory specimen. Thirteen cases had gastrointestinal complications and ten had sepsis and/or meningitis. HTLV-1 infection and hypoalbuminemia $(<3.8 \mathrm{mg} / \mathrm{dL})$ were the most common patient characteristics. Five cases died within thirty days after diagnosis of strongyloidiasis (case fatality rate $31 \%$ ). Patient background and complications were compared between the five fatalities and all other cases in Table 3. All fatal cases had pulmonary complications and systemic infection. The findings for case number 1 and 2 have been previously published as case report articles [28] (the report for case 1 was published as a Japanese article).
Table 1 Patient and Sample Charactaristics

\begin{tabular}{|c|c|c|}
\hline$n=16$ & & (\%) \\
\hline Male & 7 & (44) \\
\hline $\mathrm{Age}^{\mathrm{a}}$ & 75 & $(46-96)$ \\
\hline \multicolumn{3}{|l|}{ Underlying conditions } \\
\hline Serum albumin $(\mathrm{g} / \mathrm{dL})^{\mathrm{ab}}$ & 2.3 & $(1.1-4.2)$ \\
\hline HTLV-1 ${ }^{c}$ & 11 & (79) \\
\hline Steroid user & 5 & (31) \\
\hline Chemotherapy & 1 & (6) \\
\hline \multicolumn{3}{|l|}{ Underlying disease } \\
\hline Adult T-cell lymphoma/leukemia & 5 & (31) \\
\hline Type 2 diabetes mellitus & 3 & (19) \\
\hline Chronic heart disease & 3 & (19) \\
\hline Cervical cancer & 1 & (6) \\
\hline Rheumatoid arthritis & 1 & (6) \\
\hline Pulmonary disease & 2 & (12) \\
\hline Chronic obstructive pulmonary disease & 2 & \\
\hline Lung cancer & 1 & \\
\hline Interstitial pneumonia & 1 & \\
\hline \multicolumn{3}{|l|}{ Sample type } \\
\hline Respiratory & 13 & (81) \\
\hline Sputum & 11 & \\
\hline Bronchoscopic lavage & 2 & \\
\hline Gastro-intestine & 13 & (81) \\
\hline Stool & 11 & \\
\hline Gastric juice & 6 & \\
\hline Gastric biopsy & 1 & \\
\hline Out of life cycle organ (DS) & 3 & (19) \\
\hline Urine & 2 & \\
\hline Ascites & 1 & \\
\hline
\end{tabular}

Abbreviations: DS disseminated strongyloidiasis, HTLV-1 human T-cell leukemia virus type $1,{ }^{a}$ mean (range) was used for these values, ${ }^{b}$ total 13 cases were tested serum albumin, 'total 14 cases were tested HTLV-1

\section{Pulmonary manifestations}

Meanwhile, fifteen of the sixteen cases had pulmonary manifestations (Table 4). Acute respiratory distress syndrome (ARDS) was the most common manifestation (8/15), bacterial pneumonia (7/15) and respiratory hemorrhage including pulmonary alveolar hemorrhage (PAH) and hemoptysis (5/15) followed. Acute respiratory failure (ARF) was a common indication for pulmonary manifestations (13/15). In cases with bacterial pneumonia, pathogens detected were always enteric bacteria; 2 Klebsiella pneumoniae, 1 Escherichia coli, 1 Acinetobacter baumannii, 1 Citrobacter koseri (all pathogens were identified from sputum culture). 
Table 2 Clinical information

\begin{tabular}{|c|c|c|}
\hline$n=16$ & & (\%) \\
\hline Cases with systemic infection & 10 & $(63)$ \\
\hline Sepsis & 8 & \\
\hline \multicolumn{3}{|l|}{$\begin{array}{l}\text { (3 Klebsiella pneumoniae, } 2 \text { Escherichia coli, } \\
1 \text { Aeromonas hydrophila, } 2 \text { unknown pathogen) }\end{array}$} \\
\hline Meningitis & 5 & \\
\hline \multicolumn{3}{|l|}{$\begin{array}{l}\text { (1 Klebsiella pneumoniae, } 1 \text { Escherichia coli, } \\
3 \text { unknown pathogen) }\end{array}$} \\
\hline Cases with gastro-intestinal complication & 13 & $(81)$ \\
\hline Vomiting & 9 & \\
\hline Diarrhea & 5 & \\
\hline lleus & 4 & \\
\hline Constipation & 3 & \\
\hline Abdominal pain & 2 & \\
\hline Ascites & 2 & \\
\hline Melena & 1 & \\
\hline \multicolumn{3}{|l|}{ Treatment } \\
\hline Ivermectin & 16 & $(100)$ \\
\hline daily & 12 & \\
\hline weekly & 1 & \\
\hline + Thiabendezole & 1 & \\
\hline regimen is not clear & 3 & \\
\hline Died in 30 days from diagnosis & 5 & $(31)$ \\
\hline
\end{tabular}

\section{Radiological Findings}

For this assessment, two cases (case 8 and 12) were excluded because pulmonary strongyloidiasis findings were difficult to distinguish from underlying lung diseases; severe emphysema and interstitial pneumonia (Table 5). CXR was assessed in the remaining fourteen cases and thirteen cases had findings. Typical findings for pulmonary strongyloidiasis are shown (Figs. 2, 3, 4, 5). Ten of the thirteen cases with findings had diffuse shadow, and of those ten, four cases had opacities beginning at the hilum radiating upward to the middle sternum, like butterfly pulmonary opacity (i.e. Fig. 4). Another three cases had focal shadows. Additionally, ileum gas was detectable for ten of sixteen cases in the upper abdomen during assessment with CXR and nine of these cases had ileum gas present in the upper left abdomen.

CCT findings were assessed in nine cases. Eight of those nine cases had ground-glass opacity (GGO), and six had diffuse GGO primarily in the upper lobes (i.e. Figs. 4 and 5). The combination of GGO with interlobular septal (ILS) thickening was also a common radiologic finding (6/9). Cases 2 [28] and 16 (Fig. 5) exemplified ILS thickening with GGO, with so called crazy-paving appearance. Almost all cases (8/9) had pleural fluid.
Table 3 Comparison between survivors and non-survivors

\begin{tabular}{|c|c|c|c|c|}
\hline & \multicolumn{2}{|c|}{ Non-survivors } & \multicolumn{2}{|c|}{ Survivors } \\
\hline & $n=5$ & $(\%)$ & $n=11$ & $(\%)$ \\
\hline Male & 1 & $(20)$ & 6 & (55) \\
\hline $\mathrm{Age}^{\mathrm{a}}$ & 66.8 & $(46-81)$ & 79.8 & $(51-96)$ \\
\hline \multicolumn{5}{|l|}{ Underlying conditions } \\
\hline Serum albumin $(g / d L)^{a b}$ & 2.0 & $(1.5-2.6)$ & 2.4 & $(1.1-4.2)$ \\
\hline HTLV-1 ${ }^{c}$ & 3 & $(75)$ & 8 & $(80)$ \\
\hline Steroid user & 2 & $(40)$ & 3 & (27) \\
\hline Anti-cancer drug & 0 & & 1 & \\
\hline \multicolumn{5}{|l|}{ Underlying disease } \\
\hline $\begin{array}{l}\text { Adult T-cell lymphoma/ } \\
\text { leukemia }\end{array}$ & 1 & $(20)$ & 4 & $(27)$ \\
\hline Type 2 diabetes mellitus & 2 & $(40)$ & 1 & (9) \\
\hline Cases with pulmonary complication & 5 & $(100)$ & 10 & (91) \\
\hline $\begin{array}{l}\text { Acute respiratory distress } \\
\text { syndrome }\end{array}$ & 4 & & 4 & \\
\hline Pulmonary alveolar hemorrhage & 1 & & 2 & \\
\hline \multicolumn{5}{|l|}{ Other complication } \\
\hline Systemic infection & 5 & $(100)$ & 5 & (45) \\
\hline Sepsis & 4 & & 4 & \\
\hline Meningitis & 3 & & 2 & \\
\hline Ileus & 1 & $(20)$ & 3 & (27) \\
\hline
\end{tabular}

\section{Discussion}

There is much diversity among the manifestations of pulmonary strongyloidiasis. However, it is likely most patients present with one or more of the three most common complications; bacterial pneumonia, alveolar hemorrhage and allergic/eosinophilic manifestation from larvae $[17,22,23,25,29,30]$. In patients with HS/DS, the number of larvae in the host is continuously multiplying [12, 31]. As this happens, many larvae pass through the alveolar membranes causing, sometimes,

Table 4 Pulmonary manifestations

\begin{tabular}{lll}
\hline Pulmonary Manifestations & & \\
\hline$n=16$ & 15 & $(94)$ \\
Cases with pulmonary complication & 13 & \\
Acute respiratory failure & 8 & 7 \\
Acute respiratory distress syndrome & & \\
Bacterial pneumonia & 3 \\
Hemorrhage & 2 \\
Pulmonary alveolar hemorrhage & 1 \\
Hemoptysis & \\
Acute exacerbation of interstitial pneumonia & \\
\hline
\end{tabular}


Table 5 Chest Radiological findings

\begin{tabular}{|c|c|c|c|c|c|}
\hline \multicolumn{3}{|l|}{ X-ray } & \multicolumn{3}{|l|}{$\mathrm{CT}$} \\
\hline$n=14$ & & $(\%)$ & $n=9$ & & $(\%)$ \\
\hline Diffuse & & & Diffuse & & \\
\hline GGO & 4 & (29) & GGO & 3 & (33) \\
\hline Consolidation & 4 & (29) & GGO Consolidation & 3 & (33) \\
\hline GGO $\sim$ Consolidation & 2 & (14) & Multi-focal & & \\
\hline Multi-focal GGO & 1 & (7) & GGO & 1 & (11) \\
\hline Focal & & & Consolidation & 1 & (11) \\
\hline GGO & 1 & (7) & Focal GGO & 1 & (11) \\
\hline Consolidation & 1 & (7) & & & \\
\hline No abnormalities in lung & 1 & (7) & Broncho-vascular bundle thickening & 2 & (22) \\
\hline Costophrenic angle dull & 2 & (14) & Inter-lobular septal thickening ${ }^{a}$ & 6 & (67) \\
\hline Ileum gas in upper abdomen & 10 & (71) & Pleural fluid & 8 & (89) \\
\hline
\end{tabular}

Abbreviation: GGO ground glass opacity, aalways accompanied GGO in upper lobes

immense tissue damage. This process is the assumed cause of bacterial pneumonia and alveolar hemorrhage in HS/DS $[17,22]$.

In HS/DS, enteric bacteria may gain access to the bloodstream, lung and other organs throughout the body with the filariform larvae. This transmission pathway is considered likely in cases of sepsis, meningitis and pneumonia by enteric bacteria co-infecting patients with HS/DS [32, 33]. As possible proof of this hypothesis, all patients' bacterial pneumonia in our study had enteric bacteria as the causative pathogen.

Strongyloidiasis is considered one of the causes of infectious diffuse alveolar hemorrhage [30]. Some reports show autopsy revealed latent alveolar hemorrhages for mortal cases of acute respiratory failure with strongyloidiasis [29, 34]. Therefore, it can be assumed that alveolar hemorrhage due to strongyloidiasis does not always present with symptomatic hemoptysis.
In our cohort, almost all cases experienced more pulmonary manifestations than gastro-intestinal manifestations, and ARDS, bacterial pneumonia and pulmonary hemorrhage were common. This is compatible with past reports [17, 22, 23, 25]. No cases experienced allergic/ eosinophilic pulmonary manifestations in our study. It is thought that eosinophilic reactions are often suppressed or absent in HS/DS due to concomitant bacterial infection, immunosuppressant like steroids or HTLV-1 infection [14, 19, 23, 35-37]. Therefore, pulmonary manifestations resulting from allergic/eosinophilic stimulation may be not common in severe HS/DS.

In chronic, uncomplicated cases of strongyloidiasis, the larvae can only be detected in a gastro-intestinal specimen. However, in HS/DS cases, the larvae of S. stercoralis continuously multiply within a single host, as mentioned above. Therefore, the larvae are often

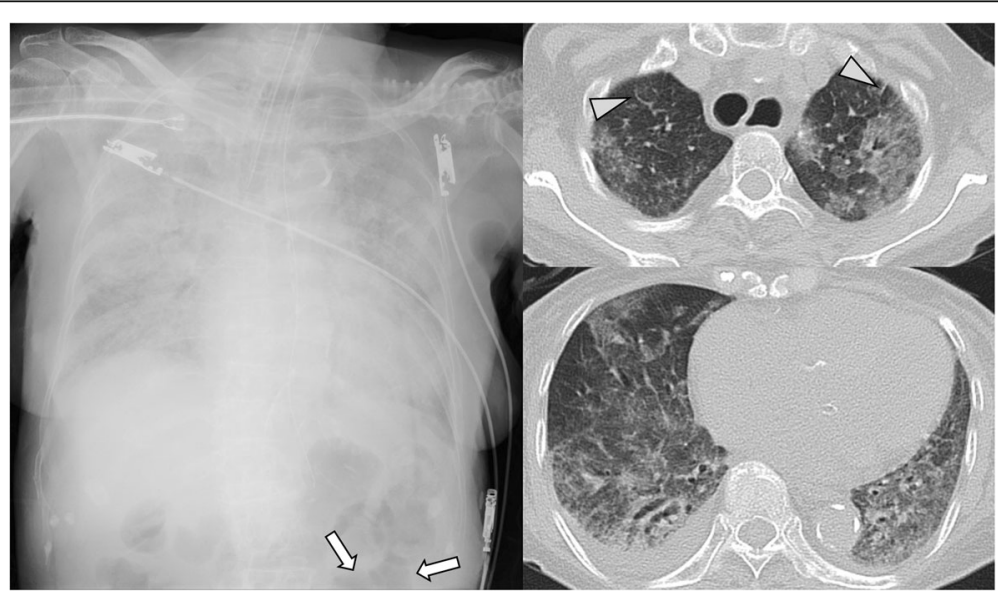

Fig. 2 Case 3: A patient with larvae detected from respiratory specimen, received steroid therapy and developed sepsis with acute respiratory failure (hyperinfection syndrome). Broncho-alveolar lavage revealed pulmonary alveolar hemorrhage and larvae. Chest X-ray shows diffuse consolidation and ileum gas (arrow). CT shows diffuse ground-glass opacity with slight inter-lobular septal thickening (arrow head) and pleural effusion 


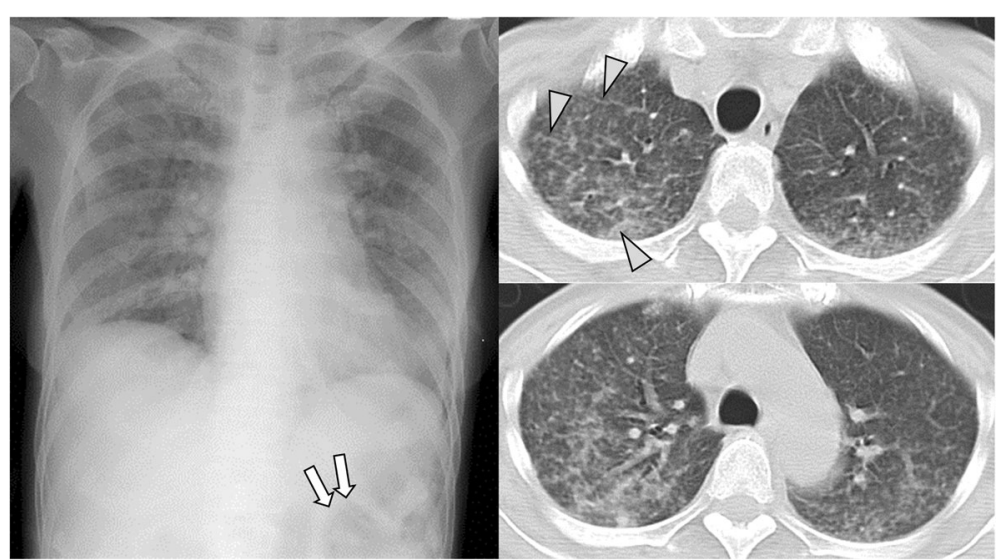

Fig. 3 Case 4: A patient with larvae detected from respiratory specimen, received steroid therapy and developed pneumonia, sepsis and meningitis with hemoptysis and acute respiratory distress syndrome (hyperinfection syndrome). Chest X-ray shows diffuse ground-glass opacity and ileum gas (arrow). CT shows multi-focal ground-glass opacity with slight inter-lobular septal thickening (arrow head)

detected within respiratory specimens $[23,38]$. Not surprisingly, almost all cases in our study had discernable larvae within their respiratory specimens. Therefore, we suggest that analysis of the respiratory specimen is a convenient and useful technique for the diagnosis of strongyloidiasis in HS/DS.

In our HS/DS cases, low serum albumin and HTLV-1 were common and this agrees with other reports $[14,15$, 19]. In patients with HTLV-1 and S. stercoralis coinfection, regulatory T-cell counts are increased and correlate with both low circulating eosinophil counts and reduced antigen-driven IL-5 production [19]. Low serum albumin has not been confirmed as a factor driving HS/ DS or the result of long term infection.

All five fatal cases had systemic bacterial infection. However, the total rate of concomitant bacterial infection was not so different from past reports [23, 39]. Additionally, the number of deaths in our study was low compared with past reports $[9,17,21]$. It is possible different treatment regimens could explain this difference. Ivermectin is currently the gold standard for the treatment of strongyloidiasis, and ivermectin was used for all cases in our study. In fact, a systematic review showed cases treated with albendezole or thiabendazole had an increased percentage of deaths among patients than cases treated with ivermectin [9]. Seggarra-Newnham recommend that treatment for HS/DS is to administer ivermectin daily until symptoms resolve and stool tests have been negative for at least two weeks [7]. The research Group on Chemotherapy of Tropical Disease, Japan, also recommends HS/DS cases complicated with acute respiratory failure commonly use daily ivermectin

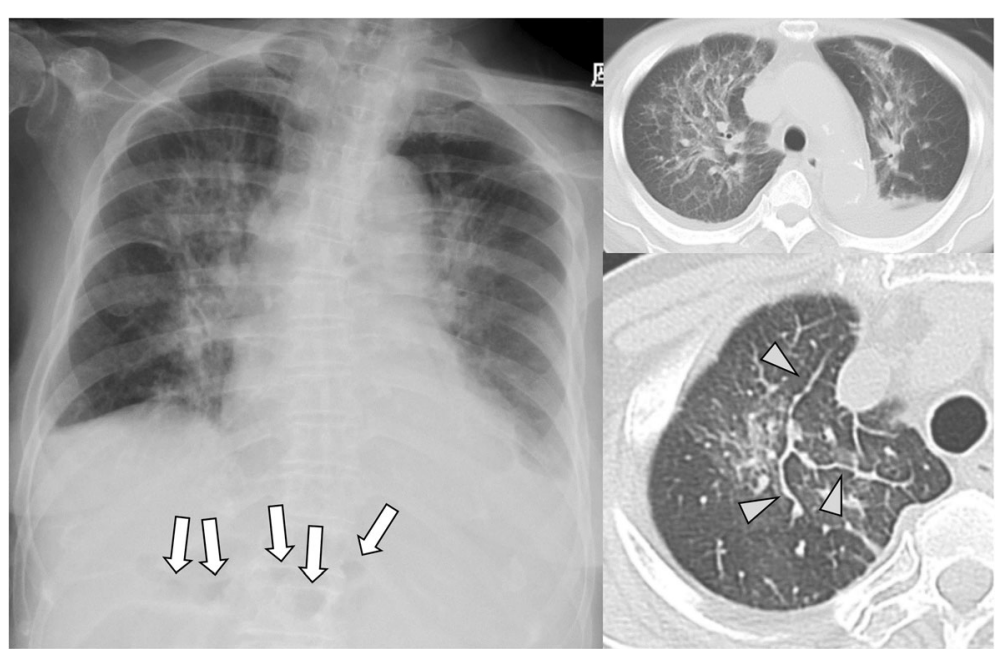

Fig. 4 Case 15: A adult T-cell lymphoma patient with larvae detected from intestinal specimen, developed pneumonia and meningitis with acute respiratory failure (hyperinfection syndrome). Chest X-ray shows diffuse consolidation and ileum gas (arrow). CT shows diffuse ground-glass opacity and consolidation with inter-lobular septal thickening (arrow head), broncho-vascular bundle thickening and pleural effusion 


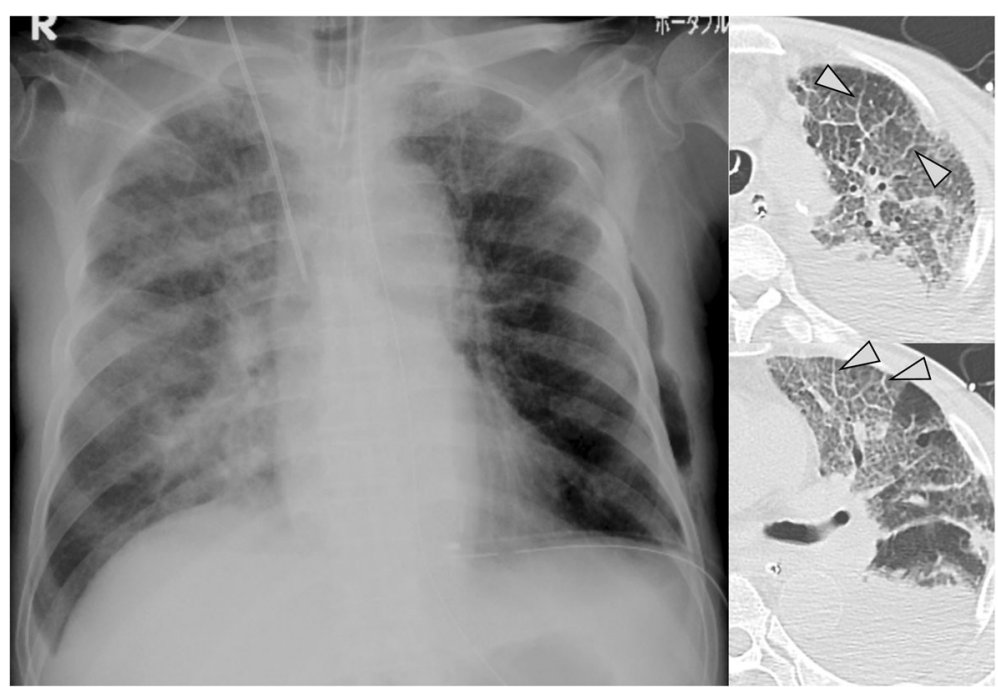

Fig. 5 Case 16: A patient with larvae detected from respiratory specimen, received steroid therapy and developed sepsis with acute respiratory distress syndrome (hyperinfection syndrome). Chest X-ray shows diffuse ground-glass opacity and consolidation in the lung, as well as a chest drainage tube in the lower left thoracic cavity. Ileum gas could not be detected. CT shows diffuse ground-glass opacity and obvious inter-lobular septal thickening (arrow head), so-called crazy-paving, and pleural fluid

until the disappearance of larvae in both sputum and stool. However, these recommendations do not have an evidence-based basis.

ILS thickening with GGO was seen often in our study, and some cases had the appearance of crazy-paving, as a characteristic finding of alveolar hemorrhage. Considering strongyloidiasis is one cause of infectious alveolar hemorrhage [30], it is assumed these findings could indicate alveolar hemorrhage as a marker for the transition stage from the latent to the symptomatic state.

CXR findings of diffuse shadows, like butterfly pulmonary opacities, are also compatible with pulmonary edema. Therefore it is possible, HS/DS cases with ARF and diffuse shadow could be mis-diagnosed as ARDS. ARDS cases with sepsis or meningitis, contracted in an endemic area of S. stercoralis, should be checked for the presence of larvae in gastro-intestinal and respiratory specimens.

Interestingly, more than half of our cases had detectable ileum gas in the upper left abdomen of CXR images. Paralytic ileus complicated with strongyloidiasis frequently occurs at the upper small intestine, because eggs deposited in the intestinal mucosa, hatch and migrate to the lumen to mature here. Therefore, ileum gas usually presents at upper left abdomen (end of duodenum to upper small intestine) [40-44], and results in our study were compatible. Although this finding deviates from the primary subject of our study, it is possible ileum gas may be an additional indicator for the presence of S. stercoralis when combined with other diagnostic factors.
Our study has certain limitations. First, this is retrospective study, therefore information regarding manifestations was limited. Additionally, radiological findings, taken at the time of diagnosis, were not performed with standardized procedures, conditions and timing. Lastly, we included only severe cases of strongyloidiasis, in our study. Pulmonary involvement is also present in chronic strongyloidiasis with mild/no symptoms, although the radiological manifestations might differ [45, 46]. Mild cases may also include pulmonary manifestations resulting from an allergic/eosinophilic response [17, 22].

\section{Conclusions}

In summary, our study describes HS/DS cases with pulmonary manifestations including, ARDS, bacterial pneumonia and pulmonary hemorrhage. CXR findings in HS/ DS frequently showed diffuse shadows. CCT findings revealed that GGO with ILS thickening was common in HS/DS, regardless of accompanying pulmonary manifestations. This CCT finding suggests alveolar hemorrhage could be used as a potential marker indicating the transition from latent to symptomatic state. Respiratory specimens are especially useful for detecting larvae in cases of HS/DS.

\section{Abbreviations}

ARDS: Acute respiratory distress syndrome; avg.: Average; BBB: Broncho-vascular bundle; CCT: Chest computed tomography; CXR: Chest X-ray; GGO: Ground glass opacity; HS/DS: Hyperinfection syndrome and disseminated strongyloidiasis; HTLV-1: Human T-cell leukemia virus type 1; ILS: Interlobular septal; PAH: Pulmonary alveolar hemorrhage 


\section{Acknowledgements}

The authors would like to acknowledge the collaboration of medical doctors listed below from affiliated hospitals in Okinawa, Japan. Dr. Tomoo Kishaba and Dr. Shin Yamashiro (Okinawa Chubu Hospital, Japan), Dr. Masato Toyama (Yonabaru Chuo Hospital, Japan), Dr. Masato Azuma (Nanbu Medical Center and Children's Medical Center, Japan), Dr. Yoko Sato (Tomishiro Central Hospital, Japan) and Dr. Kayoko Uechi (Heart Life Hospital, Japan), and all patients included in this study.

\section{Funding}

This research did not receive any specific grant from funding agencies in the public, commercial, or not-for-profit sectors.

\section{Availability of data and materials}

All data generated or analyzed during this study are included in this published article.

\section{Authors' contributions}

DN contributed to study conception, data acquisition, data analysis and manuscript drafting. SH contributed to study conception, data acquisition, data analysis, manuscript drafting and critical manuscript revision. GP contributed to study conception and critical manuscript revision. TK contributed to data analysis, manuscript drafting and critical manuscript revision. SN contributed to study conception and critical manuscript revision. TT contributed to data analysis and critical manuscript revision. TH contributed to data acquisition, data analysis and critical manuscript revision. $\mathrm{AH}$ contributed to data acquisition and critical manuscript revision. MT contributed to data acquisition and critical manuscript revision. JF contributed to data acquisition and critical manuscript revision. All authors read and approved the final manuscript.

\section{Competing interests}

The authors declare that they have no competing interests.

\section{Consent for publication}

Not applicable. The medical records of all confirmed cases were retrospectively reviewed, with identifying information removed.

\section{Ethics approval and consent to participate}

There are no ethical problems or conflict of interests with regard to this manuscript. The medical records of all confirmed cases were retrospectively reviewed, with identifying information removed. The study was reviewed and approved by the Clinical Research Ethics Committee of University of the Ryukyus (H26.8-7-695).

\section{Publisher's Note}

Springer Nature remains neutral with regard to jurisdictional claims in published maps and institutional affiliations.

Received: 28 July 2016 Accepted: 28 April 2017

Published online: 02 May 2017

\section{References}

1. Olsen A, van Lieshout L, Marti H, Polderman T, Polman K, Steinmann P, Stothard R, Thybo S, Verweij JJ, Magnussen P. Strongyloidiasis-the most neglected of the neglected tropical diseases? Trans R Soc Trop Med Hyg. 2009;103(10):967-72

2. Kline K, McCarthy JS, Pearson M, Loukas A, Hotez PJ. Neglected tropical diseases of Oceania: review of their prevalence, distribution, and opportunities for control. PLoS Negl Trop Dis. 2013;7(1):e1755.

3. Schär F, Trostdorf U, Giardina F, Khieu V, Muth S, Marti H, Vounatsou P, Odermatt P. Strongyloides stercoralis: Global Distribution and Risk Factors. PLoS Negl Trop Dis. 2013;7(7):e2288

4. Neglected tropical diseases, hidden successes, emerging opportunities [http://www.who.int/iris/handle/10665/44214]. Accessed 1 May 2017.

5. Genta RM. Global prevalence of strongyloidiasis: critical review with epidemiologic insights into the prevention of disseminated disease. Rev Infect Dis. 1989;11(5):755-67.

6. Jorgensen T, Montresor A, Savioli L. Effectively controlling strongyloidiasis. Parasitol Today. 1996;12(4):164.

7. Segarra-Newnham M. Manifestations, diagnosis, and treatment of Strongyloides stercoralis infection. Ann Pharmacother. 2007;41(12):1992-2001.
8. Bisoffi Z, Buonfrate D, Montresor A, Requena-Méndez A, Muñoz J, Krolewiecki AJ, Gotuzzo E, Mena MA, Chiodini PL, Anselmi M, et al. Strongyloides stercoralis: a plea for action. PLoS Negl Trop Dis. 2013;7(5):e2214.

9. Buonfrate D, Requena-Mendez A, Angheben A, Muñoz J, Gobbi F, Van Den Ende J, Bisoffi Z. Severe strongyloidiasis: a systematic review of case reports. BMC Infect Dis. 2013;13:78.

10. Valerio L, Roure S, Fernández-Rivas G, Basile L, Martínez-Cuevas O, Ballesteros Á Ramos X, Sabrià M, Diseases NMWGol. Strongyloides stercoralis, the hidden worm. Epidemiological and clinical characteristics of 70 cases diagnosed in the North Metropolitan Area of Barcelona, Spain, 2003-2012. Trans R Soc Trop Med Hyg. 2013;107(8):465-70.

11. Zaha O, Hirata T, Kinjo F, Saito A. Strongyloidiasis-progress in diagnosis and treatment. Intern Med. 2000;39(9):695-700.

12. Grove DI. Human strongyloidiasis. Adv Parasitol. 1996;38:251-309.

13. Yung EE, Lee CM, Boys J, Grabo DJ, Buxbaum JL, Chandrasoma PT. Strongyloidiasis hyperinfection in a patient with a history of systemic lupus erythematosus. AmJTrop Med Hyg. 2014;91(4):806-9.

14. Keiser PB, Nutman TB. Strongyloides stercoralis in the Immunocompromised Population. Clin Microbiol Rev. 2004;17(1):208-17.

15. Vadlamudi RS, Chi DS, Krishnaswamy G. Intestinal strongyloidiasis and hyperinfection syndrome. Clin Mol Allergy. 2006;4:8.

16. Concha R, Harrington W, Rogers Al. Intestinal strongyloidiasis: recognition, management, and determinants of outcome. J Clin Gastroenterol. 2005;39(3):203-11.

17. Woodring $\mathrm{JH}$, Halfhill $\mathrm{H}$, Reed JC. Pulmonary strongyloidiasis: clinical and imaging features. AJR Am J Roentgenol. 1994;162(3):537-42.

18. Cebular S, Lee S, Tolaney P, Lutwick L: Community-acquired pneumonia in immunocompromised patients. Opportunistic infections to consider in differential diagnosis. Postgrad Med 2003, 113(1):65-66, 69-70, 73-64 passim.

19. Montes M, Sanchez C, Verdonck K, Lake JE, Gonzalez E, Lopez G, Terashima A, Nolan T, Lewis DE, Gotuzzo E, et al. Regulatory T cell expansion in HTLV-1 and strongyloidiasis co-infection is associated with reduced IL-5 responses to Strongyloides stercoralis antigen. PLoS Negl Trop Dis. 2009;3(6):e456.

20. Hays R, Esterman A, McDermott R. Type 2 Diabetes Mellitus Is Associated with Strongyloides stercoralis Treatment Failure in Australian Aboriginals. PLoS Negl Trop Dis. 2015;9(8):e0003976.

21. Link K, Orenstein R. Bacterial complications of strongyloidiasis: Streptococcus bovis meningitis. South Med J. 1999;92(7):728-31.

22. Mokhlesi B, Shulzhenko O, Garimella PS, Kuma L, Monti C. Pulmonary Strongyloidiasis: The Varied Clinical Presentations. Clin Pulm Med. 2004;11(1):6-13.

23. Lam CS, Tong MK, Chan KM, Siu YP. Disseminated strongyloidiasis: a retrospective study of clinical course and outcome. Eur J Clin Microbiol Infect Dis. 2006;25(1):14-8.

24. Chu E, Whitlock WL, Dietrich RA. Pulmonary hyperinfection syndrome with Strongyloides stercoralis. Chest. 1990;97(6):1475-7.

25. Woodring $J \mathrm{H}$, Halfhill $H$, Berger R, Reed JC, Moser N. Clinical and imaging features of pulmonary strongyloidiasis. South Med J. 1996;89(1):10-9.

26. Toma H, Shimabukuro I, Kobayashi J, Tasaki T, Takara M, Sato Y. Community control studies on Strongyloides infection in a model island of Okinawa, Japan. Southeast Asian J Trop Med Public Health. 2000;31(2):383-7.

27. Tanaka T, Hirata T, Parrott G, Higashiarakawa M, Kinjo T, Hokama A, Fujita J. Relationship Among Strongyloides stercoralis Infection, Human T-Cell Lymphotropic Virus Type 1 Infection, and Cancer: A 24-Year Cohort Inpatient Study in Okinawa, Japan. Am J Trop Med Hyg. 2016;94(2):365-70.

28. Kinjo T, Nabeya D, Nakamura $H$, Haranaga $S$, Hirata T, Nakamoto T, Atsumi $E_{1}$ Fuchigami T, Aoki Y, Fujita J. Acute respiratory distress syndrome due to Strongyloides stercoralis infection in a patient with cervical cancer. Intern Med. 2015:54(1):83-7.

29. Kinjo T, Tsuhako K, Nakazato I, Ito E, Sato Y, Koyanagi Y, Iwamasa T. Extensive intraalveolar haemorrhage caused by disseminated strongyloidiasis. Int J Parasitol. 1998; 28(2):323-30

30. von Ranke FM, Zanetti G, Hochhegger B, Marchiori E. Infectious diseases causing diffuse alveolar hemorrhage in immunocompetent patients: a stateof-the-art review. Lung. 2013;191(1):9-18.

31. Mejia R, Nutman TB. Screening, prevention, and treatment for hyperinfection syndrome and disseminated infections caused by Strongyloides stercoralis. Curr Opin Infect Dis. 2012;25(4):458-63.

32. Montes M, Sawhney C, Barros N. Strongyloides stercoralis: there but not seen. Curr Opin Infect Dis. 2010:23(5):500-4.

33. Fardet L, Généreau T, Poirot JL, Guidet B, Kettaneh A, Cabane J. Severe strongyloidiasis in corticosteroid-treated patients: case series and literature review. J Inf Secur. 2007;54(1):18-27. 
34. Sunagawa K, Nishio H, Kinukawa N, Yamada T, Nemoto N, Ochiai T. An autopsy case of disseminated strongyloidiasis combined with cytomegalovirus infection. Jpn J Infect Dis. 2011;64(2):150-2.

35. Arsić-Arsenijević $V$, Dzamić A, Dzamić Z, Milobratović D, Tomić D. Fatal Strongyloides stercoralis infection in a young woman with lupus glomerulonephritis. J Nephrol. 2005;18(6):787-90.

36. Livneh A, Coman EA, Cho SH, Lipstein-Kresch E. Strongyloides stercoralis hyperinfection mimicking systemic lupus erythematosus flare. Arthritis Rheum. 1988;31(7):930-1.

37. Hirata T, Uchima N, Kishimoto K, Zaha O, Kinjo N, Hokama A, Sakugawa H, Kinjo F, Fujita J. Impairment of host immune response against strongyloides stercoralis by human T cell lymphotropic virus type 1 infection. AmJTrop Med Hyg. 2006;74(2):246-9.

38. Mora CS, Segami Ml, Hidalgo JA. Strongyloides stercoralis hyperinfection in systemic lupus erythematosus and the antiphospholipid syndrome. Semin Arthritis Rheum. 2006;36(3):135-43.

39. Geri G, Rabbat A, Mayaux J, Zafrani L, Chalumeau-Lemoine L, Guidet B, Azoulay E, Pène F. Strongyloides stercoralis hyperinfection syndrome: a case series and a review of the literature. Infection. 2015;43(6):691-8.

40. Chunlertrith K, Noiprasit A, Kularbkaew C, Sanpool O, Maleewong W, Intapan PM. A complicated case of strongyloidiasis presenting with intestinal lymphadenopathy obstruction: molecular identification. Southeast Asian J Trop Med Public Health. 2015; 46(1):1-7.

41. Cookson JB, Montgomery RD, Morgan HV, Tudor RW. Fatal paralytic ileus due to strongyloidiasis. Br Med J. 1972;4(5843):771-2.

42. O'Brien W. Intestinal malabsorption in acute infection with Strongyloides stercoralis. Trans R Soc Trop Med Hyg. 1975;69(1):69-77.

43. Yoshida $H$, Endo $H$, Tanaka S, Ishikawa A, Kondo H, Nakamura T. Recurrent paralytic ileus associated with strongyloidiasis in a patient with systemic lupus erythematosus. Mod Rheumatol. 2006;16(1):44-7.

44. Nonaka D, Takaki K, Tanaka M, Umeno M, Takeda T, Yoshida M, Haraguch Y, Okada K, Sawae Y. Paralytic ileus due to strongyloidiasis: case report and review of the literature. AmJTrop Med Hyg. 1998:59(4):535-8.

45. Esteban Ronda V, Franco Serrano J, Briones Urtiaga ML. Pulmonary Strongyloides stercoralis infection. Arch Bronconeumol. 2016:52(8):442-3.

46. Buonfrate D, Gobbi F, Beltrame A, Bisoffi Z. Severe Anemia and Lung Nodule in an Immunocompetent Adopted Girl with Strongyloides stercoralis Infection. AmJTrop Med Hyg. 2016;95(5):1051-3.

\section{Submit your next manuscript to BioMed Central and we will help you at every step:}

- We accept pre-submission inquiries

- Our selector tool helps you to find the most relevant journal

- We provide round the clock customer support

- Convenient online submission

- Thorough peer review

- Inclusion in PubMed and all major indexing services

- Maximum visibility for your research

Submit your manuscript at www.biomedcentral.com/submit 